\section{Autoantikörper gegen Tr/DNER}

W. Stöcker

Euroimmun Medizinische Labordiagnostika AG, Lübeck, Deutschland

Synonym(e) Anti-Tr/DNER-Autoantikörper; PCA-Tr-Autoantikörper; Tr-Autoantikörper

Englischer Begriff Tr autoantibodies; PCA-Tr autoantibodies; anti-Tr/DNER autoantibodies

Definition Autoantikörper gegen „Delta/Notch-like Epidermal Growth Factor-Released"-Rezeptoren (DNER) im Zytoplasma der Purkinje-Zellen des Kleinhirns.

Funktion - Pathophysiologie DNER werden sowohl in peripheren und zentralen Neuronen exprimiert als auch in Tumorgewebe (bei Antikörper-positiven Patienten).

Analytik Die Bestimmung der Autoantikörper gegen $\mathrm{Tr} /$ DNER ist mittels indirekten Immunfluoreszenztest (IIFT, - Immunfluoreszenz, indirekte) mit Gefrierschnitten von Primatenkleinhirn als Substrat möglich. Diese Antikörper sind an einer feinen Fluoreszenz des Purkinje-Zell-Zytoplasmas und einer punktartigen Färbung der Molekularschicht erkennbar. Zum monospezifischen Nachweis der Anti-Tr/DNER eignen sich der indirekte Immunfluoreszenztest (IIFT, $>$ Immunfluoreszenz, indirekte) mit transfizierten HEK-Zellen als
Substrat oder Linienblots ( $\triangleright$ Immunblot) mit aufgereinigten definierten Antigenen.

Untersuchungsmaterial Serum, Plasma oder Liquor.

Probenstabilität Autoantikörper sind bei $+4{ }^{\circ} \mathrm{C}$ bis zu 2 Wochen lang beständig, bei $-20{ }^{\circ} \mathrm{C}$ über Monate und Jahre hinweg.

Diagnostische Wertigkeit Anti-Tr/DNER werden bei Patienten mit Kleinhirndegeneration gefunden und können den ersten Hinweis auf einen zugrunde liegenden Morbus Hodgkin geben; s. a. - Autoantikörper gegen neuronale Antigene.

\section{Literatur}

Bernal F, Shams'ili S, Rojas I, Sanchez-Valle R, Saiz A, Dalmau J, Honnorat J, Sillevis Smitt P, Graus F (2003) Anti-Tr antibodies as markers of paraneoplastic cerebellar degeneration and Hodgkin's disease. Neurology 60:230-234

Graus F, Delattre JY, Antoine JC, Dalmau J, Giometto B, Grisold W, Honnorat J, Smitt PS, Vedeler CH, Verschuuren JJ, Vincent A, Voltz $\mathrm{R}$ (2004) Recommended diagnostic criteria for paraneoplastic neurological syndromes. J Neurol Neurosurg Psychiatry 75:1135-1140

Probst C, Komorowski L, de Graaff E, van Coevorden-Hameete M, Rogemund V, Honnorat J, Sabater L, Graus F, Jarius S, Voltz R, Wildemann B, Franciotta D, Blöcker IM, Schlumberger W, Stöcker W, Sillevis Smitt PAE (2015) Standarized test for anti-Tr/ DNER in patients with paraneoplastic cerebellar degeneration. Neuol Neuroimmunol Neuroinflamm 2:e68. https://doi.org/10.1212/ NXI.0000000000000068 